\title{
ESTUDO SOBRE RELAÇÃO AFROINDÍGENA, ETNICIDADE E CONTRA(MESTIÇAGEM)
}

\section{ESTUDIO SOBRE RELACIÓN AFROINDÍGENA, ETNICIDAD Y (CONTRA) MESTIZAJE}

\author{
Maria de Fátima de Andrade Ferreira \\ Universidade Estadual do Sudoeste da Bahia - UESB
}

\section{Resumo}

No presente artigo, buscamos dar uma contribuição a mais sobre a discussão dos termos etnicidade, (contra) mestiçagem e relação afroindígena, à luz de teorias da antropologia recente (GOLDMAN, 2015; LUCIANI, 2016, entre outros) e, ao que parece, "uma encruzilhada" que se caracteriza como um espaço onde se encontram diferentes caminhos que seguem sem se fundir (ANJOS, 2006), uma mestiçagem pensada sob o ponto de vista etnográfico, uma (contra)mestiçagem que "se opõem a noção de mestiçagem, mistura e sincretismo de forma radical e, também, tomam posse de tais noções, incluindoas no modo de pensar os conceitos como forças estratégicas em movimento e um lugar onde se pode falarpensar-fazer antropologia e uma experimentação etnográfica e entende a etnicidade como uma forma importante de protestos eminentemente políticos (CUNHA, 2017). Portanto, entendemos que a (contra)mestiçagem é um processo que tenta se livrar do mito das três raças (branco, índio e negro), dos (pre)conceitos e racismos e a identidade é sempre um fenômeno relacional e a etnicidade é uma ideologia, no sentido lato de fazer passar o outro pelo mesmo e pode ser mais bem entendida se vista em situação, como uma forma de organização política (CUNHA, 2017), um elemento de configurações das ações humanas nos espaços de convivências sociais, refere-se aos aspectos das relações entre grupos sociais que se reconhecem a si próprios como diferentes e possui caráter subjetivo de construção de nossas identidades sociais e hierarquias. 
Palavras-chave: Relações interétnicas. Afroindígena. Etnicidade. Teoria da (contra) mestiçagem

\section{Resumen}

En el presente artículo, hemos buscado dar una contribución a más sobre la discusión de los termos etinicidad, (contra) mestizaje y relación afroindígena, a la luz de teorías de la antropología recente (GOLDMAN, 2015; LUCIANI, 2016 entre otros) y, al que parece, "una cruce de caminos" que se caracteriza como un espacio donde se encuentran distintos caminos que siguen sin fundirse (ANJOS, 2006), un mestizaje pensado bajo el punto de vista etnográfico, un (contra) mestizaje que "se oponen a noción de mestizaje", mezcla y sincretismo de forma radical y, también, toman posesión de tales nociones, las incluyendo en el modo de pensar los conceptos como fuerzas estratégicas en movimiento y un sitio donde se puede hablar-pensar-hacer antropología y una experimentación etnográfica y entende la etinicidad como una forma importante de protestos eminentemente políticos (CUNHA, 2017). Por lo tanto, entendemos que el (contra) mestizaje es un proceso que intenta librarse del mito de las tres razas (blanco, indio y negro), de los (pre) conceptos y racismos y la identidad es siempre un fenómeno relacional y la etinicidad es una ideología, en el sentido ancho de hacer pasar el otro por lo mismo y puede ser más bien entendida se vista en situación, como acciones humanas en los espacios de convivencias sociales, se refiere a los aspectos de las relaciones entre grupos sociales que se reconocen a si propios como distintos y posee carácter subjetivo de construcción de nuestras identidades sociales y jerarquías.

Palabras Clave: Relaciones interétnicas. Afroindígena. Etinicidad. Teoría del (contra) mestizaje. 


\section{Introdução}

As inquietações e provocações sobre os termos (contra)mestiçagem, relação afroindígena e etnicidade vem aumentando a cada dia e, não é fato novo, a preocupação com os processos de discriminação que atinge a população afrodescendente e indígena, tendo nos últimos anos ocupado espaços acadêmicos e científicos, assim como, o aprimoramento das discussões e organizações indígenas, movimentos negros e afroindígenas, que se manifestam para a interlocução e tomadas de posicionamento do pensamento próprio diante do Estado, da sociedade civil organizada e de órgãos de proteção indígenas e da população afrodescendente/afrobrasileira.

Antes de tudo, é importante ressaltar que o tema relação e saberes afroindígenas vem despertando o interesse de pesquisadores (ANJOS \& ORO, 2009; ANDRELLO, 2016; BANAGGIA, 2017; BARBOSA NETO, 2012, 2017; BEVILAQUA, 2017; FLORES, 2017; GOLDMAN, 2014, 2015; LIMA, 2017; MELLO, 2007, 2014; NÓBREGA, 2017; PACHECO, 2017; PAZZARELLI, SAUMA e HIROSE, 2017; VANZOLINI, 2014, entre outros) dedicados à discussão sobre conceitos e concepções do tema e, inclusive, quando a questão se refere a teoria etnográfica da (contra)mestiçagem/(anti)mestiçagem - um processo que tenta se livrar do mito das três raças (branco, índio e negro) e de reflexões sobre etnicidade (CUNHA, 2017, p.249) como "uma forma importante de protestos eminentemente políticos" e da relação entre etnicidade e cultura, mostrando a relação destes dois fenômenos e de que modo se relacionam sem que possam ser reduzidos um ao outro, pois os grupos étnicos "são aqueles que compartilham valores, formas e expressões culturais, portanto, um conceito importante para se pensar as fronteiras das diferenças e a importância de convivências respeitosas entre elas nos espaços sociais e humanos.

A partir de então, ganha atenção especial dos antropólogos, educadores, entre outros, estimulando-os cada vez mais à reflexão sobre a forma de pensar das classes dominantes que "têm o mau costume de produzir efeitos muito reais" e, nesse sentido, temos que nos livrar do conceito de suas dimensões representacionais ou mesmo estruturais (GOLDMAN, 2015, p.654) e a novas pesquisas e discussões teóricas e estudos etnográficos. E, embora a história social dos índios, negros, mulatos, afrobrasileiros, afroindígenas, tenha notavelmente avançado nas últimas décadas, ainda são poucos os estudos dedicados às ideologias geradoras e/ou legitimadoras da discriminação, dos preconceitos, sobretudo no que toca o período 
colonial e império no Brasil e, principalmente, quando a questão se refere a (contra) mestiçagem (GOLDMAN, 2015) e/ou a (anti)mestiçagem (LUCIANI, 2016).

A partir dessa concepção, a (contra)mestiçagem é definida como uma teoria etnográfica que deve necessariamente se "apoiar em teorias nativas". Ou seja, em teorias que nunca deixam de "opor, ou de distinguir, o cruzamento, a parcialidade, a heterogênese, a modulação analógica, as intensidades, as variações contínuas, a composição e a contramestiçagem, frutos de alianças entre portugueses e demais europeus" "aos clichês dominantes da síntese, da totalidade, da miscigenação, da identificação por contraste, dos interesses, da lógica da assimilação, da fusão e da mestiçagem e/ou sincretismo" (GOLDMAN, 2015, p.657).

Nesse sentido, percebemos a possibilidade de discutir a vivência colonial, nos contatos íntimos entre brancos europeus, índios, negros e asiáticos, ressaltando as trocas e os intensos conflitos entre esses povos desde os primeiros momentos da colonização europeia.

Para tanto, é preciso desconstruir o conceito de mestiçagem (GOLDMAN, 2004, 2006; ALENCASTRO, 1985) e reconhecer o seu emprego como "uma forma de exclusão social e cultural, na medida em que esta de fato justifica e legitima a posição inferior dos nãobrancos" (COSTA, 2001, p. 144). Para tanto, é importante saber que a nação brasileira tem o seu processo de construção narrativa, sua dimensão ideológica, como nos lembra o autor, e, durante o período que vai aproximadamente do final dos anos 30 até os anos 70 do século XX, a sociedade brasileira viveu num país marcado pela dominância da ideologia da mestiçagem. Há que se considerar aqui, por fim, que a identidade nacional, no caso específico da sociedade brasileira, iniciada em torno de 1930, constituía como justificativa para marcar uma diferença da sua própria história, considerando o fim de uma política coronelista do "café com leite", sob a dominação de lideranças entre São Paulo e Minas Gerais. Além disso, a democracia sob a liderança do governo de Getúlio Vargas, por exemplo, foi marcada pelo nacionalismo e a construção de uma identidade nacional e cultural, pautada principalmente na chamada "democracia racial", com base na ideologia de mestiçagem e branqueamento. E, nesse sentido, a "sociedade democrática" foi construída através de questões de raça e etnia, provocada devido à variedade racial na sociedade brasileira, presente entre o século XIX e XX e semeia ideologias racistas e perversas contra negros, índios, mestiços. O resultado desta 
questão surgiu com um propósito: O que fazer com os escravos, neste momento, em "liberdade" e integrantes à categoria de cidadãos? Sendo que, a partir do final dos anos 70, esta ideologia vai, por diversas razões, perdendo paulatinamente sua força integradora (COSTA, 2001).

Munanga (2004) também ressalta que esta é uma problemática para se estabelecer um nacionalismo, num projeto de modernidade sob influência europeia para pensar as relações raciais. E, assim, percebe o autor que este projeto, com vistas ao desenvolvimento do processo de formação de identidade nacional buscou resolver o "problema brasileiro", pautado nas teorias da mestiçagem e branqueamento, recorrendo aos métodos eugenistas, com vistas ao embranquecimento da sociedade e, no Brasil, destacamos alguns de seus representantes: Nina Rodrigues, Silvio Romero Euclides da Cunha, Francisco José de Oliveira Viana, entre outros.

As discussões que segue pretendem apenas ser uma breve amostra desse contexto histórico, político e social que tem a intenção de apresentar concepções atuais sobre as relações afroindígenas e da teoria etnográfica da (contra)mestiçagem e reflexões sobre etnicidade, buscando demonstrar como essas questões todas se entrecruzam e podem contribuir com o enfrentamento sobre os preconceitos e a discriminação contra negros, índios e afroindígenas, afro-brasileiros na nossa sociedade. Desse modo, contribuir com ações e práticas de sociabilidade e o respeito a diferença e, também, permitir a compreensão e apropriação de categorias que sejam capazes de converter os (pre)conceitos em conceitos autônomos.

\section{Mestiçagem, identidade nacional e etnicidade: alguns apontamentos}

A formação da sociedade brasileira é caracterizada pelas relações de poder e de (des)mandos que se configurou como espaço de atribuições de valor às diferenças fenotípicas e étnico-raciais do branco europeu e, desse modo, contribuiu para a disseminação de atitudes etnocêntricas, racistas e hierárquicas do branco colonizador em relação a outros grupos humanos - o índio, o negro, o "mestiço", o "mulato", o "caboclo".

Nesse contexto capitalista, hierárquico, autoritário e de disseminação de preconceitos e discriminação contra negros, índios e mestiços, surge a ideologia perversa do branqueamento, construída por cientistas e escritores contrários à escravidão, mas carregados do racismo e da crença na inferioridade do negro, como Euclides da Cunha, Rui Barbosa, entre outros, que 
operaram baseados no sistema de dominação e subordinação do negro, na crença de um possível conflito a ser criado a partir da exigência dessa população sobre seus direitos de cidadania e ao respeito à identidade étnico-racial. Chauí (2014, p.10) considera que "as manifestações ideológicas do autoritarismo brasileiro são desvendadas a partir de sua gênese na própria estrutura autoritária da sociedade brasileira”. E, segundo Chauí (1996, p.21), podemos entender que,

O processo histórico de invenção da nação nos auxilia a compreender um fenômeno significativo, no Brasil, qual seja, a passagem da ideia de "caráter nacional" para a de "identidade nacional". O primeiro corresponde, grosso modo, aos períodos de vigência do "princípio da nacionalidade" (1830-1880) e da "ideia nacional" (1880 - 1918), enquanto a segunda aparece no período da "questão nacional" (1918-1960).

Tal como vinha sendo invocada, a ideologia do branqueamento mostra ainda seus sinais e as suas consequências e, além disso, os apelos como disposição natural de um povo e de sua expressão cultural, baseados em elementos de "caráter nacional", como afirma Chaui (1996, p.21) e, são eles: "território, densidade demográfica, expansão de fronteiras, língua, raça, crenças religiosas, usos e costumes, folclore e belas-artes”. Essas configurações e ideologias do "caráter nacional" tiveram as contribuições e dedicação com plenitude positiva em Afonso Celso, Gilberto Freyre, Cassiano Ricardo, entre outros, ou como algo negativo em Silvio Romero, Manoel Bonfim, Paulo Prado e outros, ressalta a autora.

Nesse contexto, as comunidades tradicionais, embora, hoje, tenham alcançado avanços no reconhecimento de seus direitos, na demarcação de terras e sua assistência, a apropriação e a circulação de saberes, a ocupação do cenário sociopolítico brasileiro, dentre outras questões relevantes, apresenta ainda muitas dificuldades para que a população indígena, afrodescendente e afroindígena possam gozar os seus direitos na sociedade contemporânea, inclusive de definição de territórios colonizados e não colonizados e exigem a atenção de pesquisadores que se dedicam aos estudos sobre indígenas e afrodescendentes, de movimentos negros e indígenas.

Pois, apesar do viés da luta e da resistência dos povos indígenas e afrodescendentes, no Brasil, o emprego de conceitos e concepções sobre os modos de viver e de relações entre populações tradicionais ainda se mantém provocando crueldades, discriminação, mas 
também, a constituição de coletivos multiétnicos, em lugares onde habitam ali indígenas de diferentes povos, que se relacionam entre si e com os negros, os não-indígenas, buscando demonstrar como se configuram esses espaços culturais, suas experiências, relações interétnicas e modos de vida.

Sobre essas questões, podemos observar que Sampaio (2011) em suas discussões "De caboclo à índio: etnicidade e organização social e política entre os povos indígenas contemporâneos no nordeste do Brasil", fala sobre o caso Kapinawá e destaca que o envolvimento do Estado e da sociedade na "questão indígena" deu-se a partir de três frentes de ação, a saber: com a promulgação do Estatuto do índio (Lei 6001 de dezembro de 1973), da criação em 1972, do Conselho Indigenista Missionário (CIMI) pela Igreja Católica e do surgimento de associações de "apoio ao índio", em 1978, em diversos estados. Mas também, houve a participação dos povos indígenas que formaram suas próprias associações de caráter multiétnico, em 1980, denominada de União das Nações Indígenas (UNI), buscando fortalecer a luta por direitos e a seus territórios tradicionais.

Essas e outras questões ajudaram a delinear resultados desiguais dessas campanhas e projetos, com consequências diversas para a definição clara dos direitos indígenas no Brasil. Carvalho (2011) trata de etnicidade e organização política do povo kapinawá, no nordeste brasileiro, demonstrando que o percurso de transformação histórica e de relações interétnicas desses sujeitos é de muita relevância para a etnografia do Nordeste. Além de contribuir com o reconhecimento das suas diversidades, pluralidade de modos de vida, costumes, relações de sociabilidade e, assim, pode se constituir como uma contribuição pertinente e olhar clínico sobre essas questões e valorização da (contra)mestiçagem como um movimento pertinente e valioso no combate aos preconceitos e discriminação.

Nesse sentido, é preciso desconstruir o conceito de mestiçagem, posto que, segundo Daflon (2014), este termo "possui pelo menos três empregos mais importantes. Em um dos usos mais comuns, refere-se a processos de mistura biológica de diferentes fenótipos humanos, frequentemente interpretados como diferentes "raças", portanto, a mistura racial. Este contribui de forma direta com a concepção de mestiçagem na sociedade brasileira, elaborando a "fábula das três raças". A segunda acepção citada pela autora, "nomeia uma ideologia que atravessou em maior ou menor grau as narrativas nacionais de diversos países que fizeram parte do mundo colonial ibérico", preconizando um processo de miscigenação incessante, reavivando conflitos e antagonismos que teriam sido erradicados pela mistura, 
explica a autora. E, a terceira noção de mestiçagem "pode ser empregada ainda para descrever práticas de sincretismo, fusão, bricolagem e hibridização cultural, referindo-se à combinação de costumes, valores, princípios, hábitos e práticas culturais de diferentes grupos étnicos” (p. 307), portanto, de processos de fusão cultural.

Do ponto de vista do que nos interessa aqui, ou seja, o da construção da mestiçagem, não é apenas explicável, mas necessário lembrar que as construções sobre as categorias raça e etnia são historicamente marcadas por diversas questões raciais no Brasil e, durante o século XIX e XX, inclusive com o problema vivenciado sobre o que fazer com os ex-escravos que, naquele momento, "integrados" à população nacional, traz outras questões de relações raciais e de formação do nacionalismo à moda europeia. De acordo com Munanga (2004), este processo de formação de identidade nacional no Brasil é fato e não podemos ter por base uma identidade nacional que parte de uma única cultura, a ocidental, considerada superior, eurocêntrica. Porém, como vimos, essa ideologia fundadora da nação brasileira se baseou nos "métodos eugenistas, visando o embranquecimento da sociedade" (p. 15). Desse modo, o racismo se manifesta na sociedade brasileira como um problema sério. E, sendo da sociedade, marcada pela estrutura hierárquica e racista do espaço social, "são todos por definição, problemas sociais com especificidades diferentes, engendrados ou originados pelas diferenças na sociedade, afirma Munanga (2004a, 2004b, 2003, 2006).

No entanto, é preciso destacar que pouco conhecimento a respeito da história e das condições de existência das populações indígenas, por exemplo, geram consequências e levantam contradições e ignorâncias sobre os direitos e vida indígena. Pois, mesmo com a maciça presença destes povos na sociedade brasileira e, também, com a extensa produção científica e debates atuais sobre a questão indígena, a desinformação sobre a diversidade cultural indígena no Brasil têm produzido uma pluralidade de estereótipos e preconceitos contra essa população, como ressaltam Peggion e Danaga (2016, p.11). Assim, o processo de desconhecimento contribui para que se reconheça os índios com características discriminatórias e, como destacam os autores, desse modo, são classificados por estereótipos que os definem de aculturados, assimilados, invasores de terras, selvagens e muitos outros.

É importante frisar que, entre os anos de 1950 e 1970, “as análises dos povos indígenas versavam sobre o seu provável desaparecimento. A cultura era vista, na época, 
como algo estático e a incorporação de novos elementos era tratada como perda cultural ou aculturação" (PEGGION e DANAGA, 2016, p.15). Porém, sabemos que nada disso ocorreu, foi tudo uma invenção marcada pelos preconceitos e estereótipos contra a população indígena e uma tentativa de dominação, subordinação e exclusão social, pois essas populações nunca deixaram de reconhecer a própria identidade e lutam até hoje para garantir os seus direitos, seus diferentes espaços e construção de saberes, como afirmam os autores. Por isso, "ao olharmos para os povos indígenas na atualidade nos damos conta de que precisamos repensar a forma como vemos certos conceitos", como por exemplo, a noção de cultura e de identidade "são constantemente repensadas pela antropologia e hoje sabemos que a incorporação de elementos ocidentais não diminui a cultura indígena" (2016, p.16). Além disso, a falta de conhecimento sobre as questões indígenas, os relatos de suas experiências recentes, os modos de organização e de resistência, de luta pela terra, de defesa de seus direitos e de modos de vida na contemporaneidade contribuem para ignorar a presença indígena em diferentes localidades de nosso país.

O antropólogo João Pacheco de Oliveira (2011, p.9) lembra na apresentação de sua obra "A presença indígena no Nordeste", que é preciso combater a "forma superficial e preconceituosa com que tratamos a existência do indígena no Nordeste", pois, como destaca o autor, essa questão "tem sido abordada em circuitos prestigiados e de informação, repercutindo de maneira muito negativa na naturalização e na disseminação de estereótipos seja na opinião pública, seja na formação das novas gerações de estudantes” (p. 9).

Outra questão que merece ser colocada sobre essa problemática apresentada por Oliveira (2011) se refere ao processo de ocupação colonial que se desenvolveu por meio de desigualdades, diferenças, assimetrias que reforçam a relação de mando-obediênciasubordinação que naturaliza um conjunto de ações e práticas que colocam, de um lado, o branco como superior e, do outro, os índios e negros, como classe inferior. Esse processo de classificação social foi naturalizado e os negros, índios e mestiços foram tornando-se "outros", os "estranhos" e, de diferentes formas sofrem com os impactos negativos das posturas etnocêntricas de pessoas que, cotidianamente, reproduzem relações de preconceito e discriminação, na rua, na escola e, também, contra as comunidades indígenas, ora reforçando o ideal romântico do "bom selvagem", da "pureza" que deve ser intocada e preservada, ora expressando o preconceito que associa os povos indígenas à ideia de selvageria, bestialidade e à preguiça. 
Cunha (2012, p.11-12) fala sobre essa problemática e diz que é importante não incorrer em certas armadilhas, sendo que "a maior delas é talvez a ilusão de primitivismo" e pensar que a história dos indígenas "se reduz estritamente à sua etnografia". As sociedades indígenas, como afirma a autora "de hoje não são, portanto, o produto da natureza, antes suas relações com o meio ambiente são mediadas pela história" (p.14).

Não é novo que o processo de colonização levou muitas sociedades indígenas à extinção, principalmente os índios que viviam no território dominado e colonizado pelos europeus, seja pela apropriação indevida de suas terras e utilização de armas de fogo ou em decorrência do contágio por doenças trazidas pelos colonizadores de seus países de origem, ou ainda, pelas artimanhas e políticas criadas, "visando à 'assimilação' dos índios à nova sociedade implantada, com forte influência europeia", como ressalta Cunha (2012, p.14). E, em pleno século XXI, a grande maioria dos brasileiros ainda ignora a imensa diversidade de povos indígenas que vivem no país, assim como não consegue se livrar dos preconceitos contra índios, negros, afroindígenas. Estima-se que, na época da chegada dos europeus, fossem mais de 1.000 povos, somando entre 2 e 4 milhões de pessoas. Atualmente encontramos no território brasileiro 254 povos, falantes de mais de 150 línguas diferentes", como afirma a Fundação Nacional do Índio - FUNAI (2017) e, segundo dados do censo demográfico sobre população indígena do IBGE (2010), "população indígena é de 896,9 mil, tem 305 etnias e fala 274 idiomas, afirma Cunha $(2012,1987)$.

Oliveira e Silva (2017, p. 334-335) lembram que a dizimação linguística durante a colonização europeia foi a principal estratégia para a dominação e o etnocídio indígena no Brasil e, como se pode constatar, por exemplo, nos resultados de sua pesquisa realizada nas comunidades Pataxó, que a língua portuguesa "ainda é a que tem privilégio e é oficial, mesmo dentro das escolas indígenas que tem o apoio da legislação para alfabetizar na sua língua indígena" (p.334). Essa foi uma das estratégias perversas, pois, como destacam os autores (2017), num território em que se falavam aproximadamente 1.300 línguas diferentes, a dizimação linguística foi o ponto crucial para atingir os objetivos previstos pelos colonizadores.

As formas de perseguição à população indígena foram acentuadas com a proibição do uso das línguas indígenas, explica o autor, pois há casos, por exemplo, "como a província do 
Espírito Santo, sendo sujeito a punições como a prisão, surra, e até mesmo a morte para aqueles que desobedecessem". Sendo que essa proibição amparada pelo decreto pombalino, “tinha como objetivo fazer com que os indígenas deixassem de ser 'bárbaros', adotando nomes portugueses, enquanto as línguas indígenas iam sendo esquecidas" (QUIEZZA, 2014, apud OLIVEIRA e SILVA, 2017, p.335). Apesar disso, podemos constatar que "as comunidades indígenas do sul da Bahia vivem em processo de revitalização de suas línguas indígenas tendo o maior apoio por parte das escolas indígenas". Desse modo, as comunidades e etnias desta região baiana possuem o português como primeira língua, como lembra os autores, mas, no momento, estão em processo de revitalização de suas línguas (2014, p.335).

Além da dizimação da língua, a questão de demarcação de terras, as epidemias, os processos extremados de pobreza, o uso de drogas, destacando o alcoolismo, a prostituição, criminalidade, a dependência e a degradação social são alguns fatores já considerados pelas pesquisas (OLIVEIRA, 1999) como motivos de preocupação de indigenistas, pesquisadores, movimentos e luta indígena por direitos sociais e humanos. Nordeste isso é fato. A visão assistencialista dos órgãos públicos tem chamado a atenção de setores da sociedade organizada e de pesquisas sobre os indígenas brasileiros e estão presentes nas discussões e reflexões acadêmicas contemporâneas e, nesse processo, procuram combater os estigmas, preconceitos e as formas de discriminação criadas desde o período colonial brasileiro contra os povos indígenas.

No período colonização brasileira, pessoas foram trazidas de diferentes partes da África, à força e, como lembra Goldman (2015, p.645), “os cerca de 4 milhões de pessoas que podem ter chegado ao que hoje chamamos de Brasil encontraram milhões de indígenas, vítimas de um genocídio paralelo à diáspora africana, processos que, nunca é demasiado lembrar, sustentam a constituição desse chamado mundo moderno" e destaca o autor: "é nessa história, que é a de todos nós, que coexistem os poderes mortais da aniquilação e as potências vitais da criatividade", o que significa que "o encontro entre afros e indígenas nas Américas é o resultado do maior processo de desterritorialização e reterritorialização da história da humanidade" (p. 645). A partir desse entendimento, é possível pensar também na questão dos grupos étnicos e suas fronteiras, portanto, na construção da identidade étnica e a etnicidade como uma forma de organização social e um dos padrões de compartilhamento de características sociais (BARTH, 2000, 2005). 
Nos estudos que tratam dos contextos afro-brasileiros, africano e da diáspora africana e cosmologias indígenas, as categorias etnicidade e identidade étnica aparecem de diferentes maneiras e com concepções distintas. A questão não é tão simples e não temos aqui pretensões ambiciosas de aprofundar o assunto, em especial, devido a complexidade do próprio termo que exige um tempo maior para sua discussão. Contudo, torna-se necessário uma breve apresentação do termo quando o nosso objetivo é discutir a relação afroindígena e as contribuições da teoria etnográfica da (contra)mestiçagem para a desconstrução da concepção de mestiçagem.

De acordo com Cunha (2017, p.240), por exemplo,

Uma maneira de colocar a questão é indagar-se sobre a substância da etnicidade, substância que já foi pensada em termos biológicos, quando se falava de raças e de sua heterogeneidade. A noção de cultura veio substituirse à de raça, dentro de um movimento que se quis generoso - e certamente o foi - mas que acabou transferindo à noção de cultura reificação semelhante à noção de raça. Mas essa não é agora a questão: como cultura era adquirida, inculcada e não biologicamente dada, também podia ser perdida. Inventou-se o conceito de aculturação e com ele foi possível pensar - para gáudio de alguns, como os engenheiros sociais, e para pesar de outros, entre eles vários antropólogos - na perda da diversidade cultural e em cadinhos de raças e culturas.

Cunha (2017, p.240) lembra que "Não se trata só do Brasil, é claro. Esse foi um problema de quantos países se viram diante da tarefa de construir uma nacionalidade". A partir dessa concepção de etnicidade, podemos considerar também que a categoria mestiçagem precisa ser debatida e, para isso, é preciso propor a abertura para o diálogo etnográfico orientado a favor da (contra)mestiçagem/(anti)mestiçagem e entender que o termo afroindígena, como afirma Goldman (2014), tem justamente uma origem afroindígena, como no caso dos militantes afroindígenas do Artemanha e do Umbandaum de Caravelas, Bahia, que estão tentando se livrar do "mito das três raças" (MELLO, 2003); um conceito elaborado por pessoas que gostam de pensar a si mesmas como afroindígenas, de pensar "aprender que "afroindígena" quer dizer muitas coisas, "uma origem mítica, um modo de expressão artística (MELLO, 2003, p.73). Portanto, conforme a compreensão sobre essas questões, observamos que é preciso considerar a importância de uma antropologia "que se concentra nas diferenças enquanto tais, que leva efetivamente a sério e parte do que as pessoas pensam e que aposta 
que são apenas os problemas que elas levantam que permitem manter-se em movimento, escapar dos clichês que nos assolam e, assim, pensar diferente", como afirma Goldman (2014, p.219).

No item a seguir apresentamos uma breve discussão sobre essa relação, a que denominamos relação afroindígena, e também sobre as teorias da (contra)mestiçagem com objetivo de aprofundar melhor as reflexões sobre as contribuições de uma antropologia que "encara as diferenças, que leva a sério o que as pessoas pensam, que é capaz de se manter afastada dos clichês que nos assolam e, assim, pensar diferente" (GOLDMAN, 2014) o que nos leva a buscar pistas para pensar algumas transformações.

\section{Relações Afroindígenas e teorias da (contra)mestiçagem}

As teorias etnográficas da (contra)mestiçagem ameríndia e afro-americanas ou afroindígenas são responsáveis pelas provocações e mudanças sobre a forma de pensar as relações entre índios, negros e brancos e, nesse processo, buscam discutir questões importantes como a performance e a poética do corpo, da voz, das expressões artísticas e culturais diversas e vem ocupando o campo da Ciências Sociais brasileira, amplamente divulgada pela Antropologia Social e Cultural.

Assim, emergem descrições etnográficas que nos fazem pensar os encontros afroindígenas e colocam em diálogo as produções etnográficas e reflexões teóricas que contribuem para se repensar os conceitos, as concepções e definições relacionadas ao seu objeto de estudo e relações afroindígenas.

Goldman (2015) chama a atenção sobre a importância das etnografias recentes que vêm mostrando a riqueza com a qual a relação afroindígena é pensada pelos coletivos nela interessados e, busca as contribuições do princípio da irredução em Latour (1994) e da concepção de Losonczy (1997) sobre relações interétnicas, nas quais não se admite a ignorância recíproca, a violência aberta e nem a fusão homogeineizadora para fundamentar as suas discussões sobre os agenciamentos entre afrodescendentes e ameríndios e pensar essa relação.

Como exemplo, o autor (2017, p.11) cita o trabalho de dissertação de Mello (2003) sobre a relação afroindígena para falar da importância de desenvolver uma reflexão sobre os sentidos do que “seria na superfície um fenômeno apenas 'identitário', como se costuma 
dizer. Ao fugir desse clichê - procuramos a identidade e a unidade como outrora os colonizadores procuravam o chefe [...]" e, assim, ressalta que Mello "evitou cuidadosamente de tentar determinar o que seus amigos do Grupo Afroindígena de Antropologia Cultural, na pequena cidade de Caravelas, estariam 'realmente' querendo dizer quando se afirmam afroindígenas", preocupando-se com o que eles dizem, pensam, falam a respeito de si mesmos, dos outros e do mundo. Goldman procura mostrar que a relevância desse estudo se evidencia no modo de pensar essa relação entre os mundos afro e indígena, pois, foge do clichê que já se desgastou e perdeu o seu sentido, o da lógica colonizadora e simplificadora da realidade, afirmando que Mello (2003)

[...] preferiu seguir de modo detalhado e profundo, o que eles efetivamente dizem, fazem e, sobretudo, pensam a respeito de si mesmos, dos outros e do mundo. Pôde aprender com eles, assim, que afroindígena não precisa necessariamente ser entendido como algo "da ordem da identidade, nem do pertencimento, mas do devir" - "do que se torna, do que se transforma em outra coisa diferente do que se era e que, de algum modo, conserva uma memória do que se foi" (GOLDMAN, 2017, p.11-12)

Além disso, pauta-se nos contos irônicos de Borges (1974) e do jazz em Guattari (1993), este último sem qualquer referência ao universo indígena e, busca explicar as relações de força, poder, como se deu "o processo de reterritorialização que se seguiu à brutal desterritorialização de milhões de pessoas no movimento de origem do capitalismo com a exploração das Américas pela utilização do trabalho escravo" (2015, p.643) e outras questões que possibilitaram as articulações

dos agenciamentos que combinaram, por um lado, dimensões de diferentes
pensamentos de origem africana com aspectos dos imaginários religiosos
cristãos e do pensamento ameríndio e, por outro, formas de organização
social tornadas inviáveis pela escravização com todas aquelas que puderam
ser utilizadas, dando origem a novas formas cognitivas, perceptivas, afetivas
e organizacionais. Tratou-se, assim, de uma recomposição, em novas bases,
de territórios existenciais aparentemente perdidos, do desenvolvimento de
subjetividades ligadas a uma resistência às forças dominantes que nunca
deixaram de tentar sua eliminação e/ou captura (2015, p.643).

De acordo com Pazzarelli, Sauma e Hirose (2017, p.9), esse movimento coletivo "que começou a mais de uma década e que, ao que tudo indica, continuará por diversos caminhos”, 
de caráter transversal e em sua diversidade, contribui com pesquisas com e sobre povos "que estão perpetuamente na mira de políticas e ações violentas e colonizadoras, que nem por isso se submetem às mesmas"; desse modo, verificamos que essas coletividades, como afirmam os autores, "não estão a mercê dos referenciais integracionistas da mistura que são utilizados, de fora, para dissolver as suas potências" (p.9).

Goldman (2015) afirma que essas novas relações e parcerias são estabelecidas entre os povos indígenas e não indígenas e são evidenciadas nos crescentes movimentos culturais e artísticos e relações afroindígenas, nas quais, a mistura, a identidade e a alteridade se intercruzam produzindo ação e movimentos interculturais, estabelecendo diálogo com as teorias. E, conforme a sua concepção, o encontro afroindígena é o maior movimento de desterritorialização e retorritorialização da história. Considerando-se que o processo de colonização do Brasil deixou marcas difíceis de serem apagadas, os acontecimentos, a exploração, as ideologias racistas e perversas são os principais elementos da "ocupação das Américas, tendo como consequências o genocídio de seus habitantes, com a utilização do trabalho escravo africano por meio de uma violenta diasporização - foi predominantemente pensado de forma simplificadora, sob a chave decodificadora da dominação branca" (p.1) e, essa é uma condição substantiva para desconstruir o mito das três raças e suas formulações.

Em seu trabalho sobre "Quinhentos anos de contato": por uma teoria etnográfica da (contra) mestiçagem”, Goldman (2015, p.641) fala sobre o que denomina, provisoriamente, de "relação afroindígena", isto é, "os agenciamentos entre afrodescendentes e ameríndios" e campo empírico de sua investigação no candomblé de nação angola, suas origens e sincretismos, apresentando algumas considerações sobre o seu modo de pensar que ainda considera com um "caráter incerto e aberto" e, coloca as sínteses e as reduções sob desconfiança. Isto porque, conforme o seu modo de perceber a relação afroindígena, é possível caracterizá-la como uma relação com

[...] alto potencial de desestabilização do nosso pensamento e que, por isso mesmo, deve estar no coração de uma antropologia que encara as diferenças, que leva a sério o que as pessoas pensam, que é capaz de se manter afastada dos clichês que nos assolam e, assim, pensar diferente (GOLDMAN, 2015, p.541).

Ainda, de acordo com o autor (2015), para tratar da questão da relação afroindígena ele procura extrair "algumas conclusões provisórias a partir da justaposição de dois casos etnográficos específicos” e, nessa perspectiva, pauta-se no princípio de redução de Bruno

\begin{tabular}{l|l} 
Revista RBBA & Revista Binacional Brasil Argentina
\end{tabular} 
Latour. São eles: não reduzi-la de antemão a uma pura questão identitária; e, ao mesmo tempo, não negar a priori que a identidade possa ser uma dimensão importante do fenômeno" (p.642). Do mesmo modo, Goldman (2017) procura ressaltar a importância dessa formulação nas pesquisas realizadas por Mello (2003, 2007, 2014, 2017a, 2017b) em Caravelas, BA, com um grupo de militantes afroindígenas, considerando que se deve "pensar essa questão de um modo em que nada seja reduzido de antemão a simples reação à dominação branca, nem à mera oposição entre duas identidades, não importando se estas são como 'primordiais' ou como constituídas por "contraste"” (2017, p. 12). Também porque se trata "de livrar a noção de suas matizes substancialista e encará-la decididamente como uma relação, pensada no sentido forte do termo: por 'relação afroindígena' [...] não se pretende apenas designar uma relação que uniria conjuntos 'afros' e 'indígenas' preexistentes, mas, antes, tomá-la como um modo particular de articular diferenças" (p.12).

Ao que tudo indica, a forma de Goldman (2014, 2015, 2017) pensar a (contra)mestiçagem e a relação afroindígena exige uma nova concepção de ator e, nesse sentido, a Teoria Ator-Rede de Latour (2012) poderá permitir mudanças significativas nessa direção, pois sua "antropologia simétrica" nos ajuda a entender que as associações, advertências, proposições e procedimentos adotados para o desenvolvimento da Teoria AtorRede (ANT), confere lugar à natureza e às coisas, assim como dos modos de ser dos humanos e de seus artefatos, contrariando o binarismo entre natureza e cultura e/ou sujeito e objeto, permitindo associações, conexões e desconexões heterogêneas. Sendo assim, demonstra que há uma abertura para construir "uma arquitetura intelectual da forma de pensar e fazer ciência, a qual ele apresenta de forma sistemática em sua obra "Reagregando o social: uma introdução à Teoria do Ator-Rede" (2012). De acordo com sua compreensão, toda relação é complexa e "relacionar-se com um ou outro grupo é um processo sem fim constituído por laços incertos, frágeis, controvertidos e mutáveis. [...] a qualquer momento, os atores podem ser enquadrados num grupo - às vezes, em mais de um” (p.27).

Latour (2012) desenvolveu a Teoria Ator-Rede como forma de traçar pontos de conexão e desconexão que fluem entre os "objetos" e, segundo a sua concepção, as pessoas não esperam das ciências verdades definitivas, prontas, acabadas, pois a produção do conhecimento é tomada como uma ação eminentemente coletiva e, cabe a todos os 
participantes, a cada estudo, procurar os elementos de diferentes mundos sociais que, na sua concepção, não são realidades dadas e nem aguardam a sua mobilização, além de suas interconexões, as aproximações, as ligações transversais e as rupturas próprias de cada contexto

\begin{abstract}
Nosso passado começa a mudar. Enfim, se jamais tivéssemos sido modernos, pelo menos não da forma como a crítica nos narra, as relações tormentosas que estabelecemos com as outras naturezas-culturas seriam transformadas. $\mathrm{O}$ relativismo, a dominação, o imperialismo, a má fé, o sincretismo seriam todos explicados de outra forma, modificando então a antropologia comparada $(2012,1994$, p.16).
\end{abstract}

A partir desse entendimento de Latour $(2012,1994)$ buscamos as contribuições de Arruti (2001, p.215-216) quando explica que, desde a década de 1950, os estudos sobre as relações interétnicas e os temas de interesse começam a ultrapassar os limites dos dualismos que marcaram, por exemplo, uma boa parte da Antropologia e da Sociologia brasileira que se preocupava com as oposições binárias entre índios e brancos, negros e brancos, tornando os contrastes mais complexos e incluem outros grupos minoritários, inclusive "a confrontação cruzada entre eles, em que a dualidade entre ‘o branco' e o 'outro' já não é mais a chave explicativa de tudo". Nesse sentido, podemos observar que,

A exclusividade do interesse nas cosmologias nativas, mitologias heroicas, estruturas de parentesco e sistemas de diagnóstico e cura, que marcam a antropologia americanista, cede cada vez mais a uma contaminação desses temas por questões relacionadas aos contextos coloniais e tutelares, à mobilidade geográfica e social e, finalmente, às questões relativas à identidade. Dado o crescente conhecimento e reconhecimento públicos da mobilização política de populações que se imaginam, se organizam e se apresentam como indígenas por todo o Continente, o tema da identidade étnica é cada vez menos inevitável, esteja a sua abordagem vinculada ou não ao quadro teórico da etnicidade (ARRUTI, 2001, p.2017).

A partir desse entendimento de Arruti (2001), retomamos o pensamento de Goldman (2015) sobre a relação afroindígena, quando se propõe, a partir do princípio de irredução de Bruno Latour (1994) e, também, apoiado em Losonczy (1997), pensar essa relação, observando que,

Trata-se, basicamente, de pensar a relação afroindígena de modo que não a reduza a simples reação à dominação branca, nem à mera oposição entre duas identidades - não importa se tidas como "primordiais" ou como constituídas por "contraste". Ao contrário, trata-se de pensar essa relação a partir das alteridades imanentes que cada coletivo comporta e que devem ser 
relacionadas com as alteridades imanentes de outros coletivos, traçando espaços de interseção em que as chamadas relações interétnicas não são redutíveis nem à ignorância recíproca, nem à violência aberta, e nem à fusão homogeneizadora (GOLDMAN, 2015, p.642).

Nas suas reflexões sobre a "Historia de um contacto forzado: negros, indígenas y blancos", Losonczy (2006, p.51-64), analisa as relações interétnicas de negros e índios em Chocó, Colombia, em especial os Emberá e suas consequências, falando das tramas que se colocavam como forma de separar índios e negros e, apesar das leis severas e dos castigos por qualquer ato de desobediência, os contatos entre as etnias aconteciam de modo forçado e eram inevitáveis, marcando o passado e o presente dos negros-colombianos. Segundo a autora, na região colombiana do Chocó, onde sua população partilha o território e significativa parcela de um mesmo universo ritual, econômico e de parentesco, as relações entre eles marcaram suas histórias, percursos sociais e na configuração da identidade étnica,

Estas disposiciones legales que regieron las relaciones interétnicas coloniales desde princípios del siglo XVI hasta fines del XVIII, crearon uma situación cuyas repercusiones seguirán marcando la existência social de los descendientes libres de los esclavos em el Chocó y sus relaciones com los indígenas: contribuyeron por uma parte al olvido de las lenguas maternas y al refugio de los dioses y ritos africanos tras los nombres y las representaciones de los santos católicos, y de la prohibición tácita, pero respetada por ambos bandos, de cualquier matrimonio interétnico (LOSONCZY, 2006, p.53).

Por tudo que foi apresentado na interlocução com Goldman (2015), Losonczy (2006), Arruti (2001), entre outros, podemos dizer que as comunidades tradicionais se destacam pela configuração étnico-racial e, em muitas delas, os agenciamentos possíveis da diferença são visíveis. Sendo que as noções de agência são construídas de forma diversa em culturas diferentes e por segmentos diferentes da mesma sociedade (TRATHERN, 1985, p.65) e, como afirma Viveiros de Castro (2015, p.20), “a Antropologia está pronta para assumir integralmente sua verdadeira missão, a de ser teoria-prática da descolonização permanente do pensamento".

O termo "relação afroindígena" é utilizado por Goldman (2003) para designar os agenciamentos entre afrodescendentes e indígenas no continente americano e, de acordo com Mello (2014), afroindígena "seria da ordem do devir", "do que se torna, do que se transforma 
em outra coisa diferente do que se era e que, de algum modo, conserva uma memória do que se foi” (MELLO, 2003, p. 95), um “devir-afroindígena” que, funciona, por um lado, como meio, um intercessor por onde passam as ideias, ações políticas, obras de arte e seres do cosmos, e, por outro lado, como "um produto inacabado ou efeito provisório de encontros singulares que envolveriam fluxos de "história" e "memória", afirma a autora.

Para falar da relação afroindígena e da contramestiçagem é importante retomar a discussão sobre o processo de formação da sociedade brasileira e sublinhar que, durante os períodos históricos e sociais da construção desta sociedade, desde a colonização portuguesa aos dias atuais, índios e negros africanos foram se encontrando por diferentes motivos, inclusive para garantir proteção e sobrevivência, assim como foram formando relações de parentesco, apropriação de territórios e formação de comunidades tradicionais específicas, onde as trocas de saberes e de conhecimentos são continuamente apresentadas como formas de entrosar-se, unir-se. Nesse sentido, Goldman (2015) observa que é fundamental desconstruir os conceitos e concepções colonizadoras e discutir a relação afroindígena sem submetê-la à subordinação da "sociedade dos brancos" e ao que foi pensado e se convencionou chamar "mito das três raças"., "um triângulo encabeçado pelos brancos" (p.646).

Sauma (2014) também busca desconstruir os conceitos colonialistas e autoritários e observa em sua pesquisa intitulada "Entrosar-se, uma reflexão etnográfica afroindígena", que a análise da noção de entrosamento possibilitou uma reflexão sobre a concepção relacional de entrosamento que se replica nas formulações corporais dos Filhos do Erepecuru, população de ribeirinhos-castanheros-coletivos-remanescentes-quilombolas da mesorregião do Baixo Amazonas, município de Oriximiná, permitindo observar o efeito da comparação entre campos etnográficos indígenas e de matriz africana, conclui a autora.

Atualmente, constatamos que muitos movimentos artísticos e culturais vêm surgindo em diferentes partes do Brasil e América Latina, nos quais as "Pessoas, Acontecimentos e Objetos de Arte" (MELLO, 2007), como "um jogo de produção de novas sensibilidades, continuamente engendradas em um encontro de fusão entre os mundos externo e interno" (p. 169) e o que se pode chamar de “uma 'teoria afroindígena da ação', através dos usos do conceito nativo de 'irradiação' em sua produção artística, práticas espirituais, intervenções políticas e transformações ecológicas do meio em que vivem" (p.2). O grupo afroindígena de Caravelas, dos movimentos culturais Arte Manha e Umbandaum que atuam no espaço 
caravelense e têm tentado pensar diferente sobre as trocas e saberes entre negros e índios e, como afirma Mello (2014, p.236), ao provocar a discussão e buscar formas de instigar as pessoas a pensar, "a arte produzida pelo grupo funciona como um catalizador existencial que afeta tanto os fluxos que vem 'de fora, isto é, os fluxos majoritários com que lidam cotidianamente, quanto o fora dentro da gente' [...]"

Estes movimentos, ao que nos parece, são formas de expressão que tem como intenção construir e pensar relações interculturais, o diálogo que traz à luz novas conexões e diferenciações entre os coletivos e as formas de socialização de seus saberes tradicionais, suas variadas formas de encontro, e, ao que tudo indica, tem contribuído com as análises identitárias e o desenvolvimento de reflexões etnográficas sobre os processos de identificação e diferenciação de grupos étnico-raciais, de coletivos indígenas e de matriz africana, assim como, amplia os conhecimentos sobre a antropologia afroindígena e da contramestiçagem. E, desse modo, também pensa Goldman (2014, 2015), ao buscar construir uma teoria etnográfica da (contra)mestiçagem - uma possibilidade de combater os mitos, a estatização, ou branqueamento da relação afroindígena que não apenas marcou a forma de pensar e as investigações acadêmicas, mas também, "o encontro e a relação afroindígena que foram devidamente submetidos à 'sociedade dos brancos' e pensados na forma daquilo que se convencionou a chamar "mito das três raças"”(2015).

Concordamos com Sauma (2014, p.257) nas suas reflexões afroindígenas quando afirma que "até agora tenho evitado uma consideração mais direta sobre o que seria uma antropologia afroindígena" em suas discussões etnográficas, "até mesmo nos escritos compostos para momentos de reflexão" e, declara: "Minha hesitação tem uma explicação bem simples: acho esse conceito extremamente difícil, apesar de aparentar simplicidade" (p.257). O termo afroindígena apresenta uma complexidade de sentidos e significados que devem ser investigados e, para a autora (2014), foi possível descrever a dificuldade inerente acerca desta questão por ela observada, "por meio de uma consideração dos processos de identificação e diferenciação que a noção afroindígena traz consigo", diz a Sauma (2014).

Os "agenciamentos entre afrodescendentes e ameríndios", denominados por Goldman (p.642), como "relação afroindígena" que, conforme o autor, é um termo derivado de seu campo de investigação, o candomblé de nação angola, com seus infindáveis debates sobre 
origens e sincretismos [...]" e que tem suscitado questões relevantes para suas pesquisas. A partir desse entendimento, o autor busca Mello (2003, p.73) para explicar que a relação afroindígena "não se trata de uma simples 'justaposição de duas influências ou formas de expressão [...] distintas e irredutíveis', mas de 'uma terceira forma, com características próprias'.

A partir dessas considerações de Goldman (2014), Mello (2003), podemos perceber que o movimento Arte Manha e o Umbandaun pode ser reconhecido como uma mistura indígena na cidade de Caravelas, Extremo Sul da Bahia - Brasil, pois é um espaço utilizado por pessoas que se apresentam com manifestações culturais e artes que representam questões da experiência de ser indígena na cidade, da construção do espaço de dança, artes, discussões e reflexões para demonstrar as suas crenças, saber, saber-fazer na cidade e região, a construção de um espaço enquanto aldeia, e como pessoas as pensam coletivamente sobre a constituição desse espaço enquanto aldeia, como pessoas, indivíduos-sujeitos que pensam sobre a constituição da sua indianidade nesse ambiente cultural e de vida, um contexto de movimentos culturais que constroem e reconstroem as suas histórias.

\section{Considerações finais}

Falar de etnicidade não é tarefa muito fácil, é um termo complexo e dinâmico que traz muitas configurações políticas, culturais e sociais, mas percebemos a importância dessa introdução ao fenômeno que vem estimulando reflexões e discussão de diferentes pesquisadores, das diversas áreas do conhecimento, principalmente, quando a intenção é desmistificar categorias que se estabeleceram como ideologias do branqueamento da sociedade por meio do uso de teorias contraditórias e racistas (como exemplo de Nina Rodrigues, Oliveira Viana, Silvio Romero, entre outros) para dar conta de uma realidade que a sociedade europeia importava como base de qualificação da identidade nacional brasileira.

Assim, de um lado, percebemos que é preciso discutir as relações entre negros, índios, afroindígenas, e os apontamentos que aqui apresentamos se referem à questão que exige uma nova interpretação da mestiçagem e valorizar um viés teórico etnográfico que se constrói como (contra)mestiçagem (GOLDMAN, 2015) e se apresenta como uma possibilidade de pensar conceitos de etnicidade, raça, etnia, mistura, entre outras, e, nesse processo, quebrar paradigmas autoritários que promovem as relações hierarquizadas, contraditórias, 
preconceituosas e de discriminação contra o negro, o índio, o mestiço, o "mulato", o "caboclo".

Nesse sentido, propomos que as relações afroindígenas sejam valorizadas como um ponto de partida para se pensar as relações sociais entre pessoas e grupos, de diferentes culturas, de diversidade de modos de ser e saber-fazer e, de também se relacionar com os “outros", respeitando a sua forma de pensar negro, índio, afroindígena, de acordo com suas formas de manifestações políticas e culturais.

E, assim com Mello (2014, p.23), entender que afroindígena "não é apenas a justaposição de dois polos ou de duas formas de expressão - africana e indígena - distintas e irredutíveis entre si", mas seria uma terceira forma, que a autora apresenta "com características próprias que revelam um processo de aliança ou uma entre-captura entre negros e índios tendo como marco o início do processo de colonização".

Trata-se, portanto, de buscar mudanças de concepções sobre termos que não cabem mais nas relações sociais e exigem a abertura do diálogo plural e não devem escapar das discussões sobre a diversidade e respeito à diferença.

\section{Referências}

ALENCASTRO, L. F. de. Geopolítica da mestiçagem. Novos Estudos, n. 11. Jan de 1985, p. 49-63. Tradução Maria Lúcia Montes. Disponível em: http://novosestudos.uol.com.br/produto/edicao-11/. Acesso em: 20 de março de 2018.

ANDRELLO, G. Nomes, posições e (contra) hierarquia: coletivos em transformação no Alto Rio Negro. Revista Ilha. v. 18, n.2, p. 57-97, 2016. Disponível em: https://periodicos.ufsc.br/index.php/ilha/article/view/2175-8034.2016v18n2p57; acesso: dezembro 2017.

ANJOS, J. C. G. dos. No território da linha cruzada: A cosmopolíticas afro-brasileira. Porto Alegre: Editora da UFRGS, 2006.

ANJOS, J. C. G. dos; ORO, A. P. Festa de Nossa Senhora dos Navegantes em Porto Alegre: sincretismo entre Maria e Iemanjá. Porto Alegre: SMC, 2009.

ARRUTI, J. M. A. Agenciamentos políticos da "mistura": identificação étnica e segmentação negro-indígena entre os Pankararú e os Xocó. Estudos Afro-Asiáticos, ano 23, n. 2, p. 215 254, 2001. Disponível: http://www.scielo.br/scielo.php?script=sci_arttext\&pid=S0101546X2001000200001\&lng=en\&nrm=iso\&tlng=en; acesso: novembro de 2017. 
BANAGGIA, G. Conexões afroindígenas no jarê da Chapada Diamantina. Revista de @ ntropologia da UFSCar (R@U), v. 9, n. 2, jul-dez de 2017, São Carlos, SP: UFSCar, 2017. p. 123-134. Disponível em: http://www.rau.ufscar.br/wpcontent/uploads/2017/12/07_Gabriel_Banaggia.pdf; Acesso em: 23 de janeiro de 2018.

. Conexões afroindígenas no jarê da Chapada Diamantina. Anais do $\mathbf{4 0}^{\circ}$ Encontro Anual da ANPOCS - Associação Nacional de Pós-Graduação e Pesquisa em Ciências Sociais. ST1 - Antropologias afroindígenas: contradiscursos e contramestiçagens. 2016. Disponível em: https://www.anpocs.com/index.php/papers-40-encontro/st-10/st01-8/10133conexoes-afroindigenas-no-jare-da-chapada-diamantina/file Acesso em: 23 de janeiro de 2018. p.1-16

BARBOSA NETO, E. R. A geometria do axé: o sincretismo como topologia. Revista de Antropologia da UFSCar (R@A), jul./dez. 2017, p. 171-183. Disponível em: http://www.rau.ufscar.br/wp-content/uploads/2017/12/10_Edgar_Rodrigues.pdf. Acesso em: 12 de janeiro de 2018.

O batuque e a linha cruzada: variações sobre os sistemas etnolitúrgicos afrobrasileiros. In Anais do $36^{\circ}$ Encontro Anual da ANPOCS - Associação Nacional de PósGraduação e Pesquisa em Ciências Sociais. GT 23 Novos modelos comparativos: investigação sobre coletivos afro-indígenas. 2012. Disponível em: https://www.anpocs.com/index.php/papers-36-encontro/gt-2/gt23-2/8101-o-batuque-e-alinha-cruzada-variacoes-sobre-os-sistemas-etnoliturgicos-afro-brasileiros/file Acesso em: 20 de janeiro de 2017.

BARTH, F. Etnicidade e o conceito de cultura. Antropolítica - Revista Contemporânea de Antropologia e Ciências, n. 19, p. 15-30, 2005. Disponível em: http://www.uff.br/antropolitica/revistasantropoliticas/revista_antropolitica_19.pdf Acesso em: 20 de março de 2005.

BEVILAQUA, C. A Aldeia Vertical: mistura indígena na cidade do Rio de Janeiro. Mundo Amazônico, v. 8, n. 2, 2017, p. 1-19. Disponível em: https://doi.org/10.15446/ma.v8n2.64491 Acesso em: 14 de dezembro de 2017.

CARVAlHO, M. R. G. de. À guisa de apresentação. Cadernos do LEME, v. 3, n. 2, p. 8891. Jul/dez. 2011. Disponível em: http://www.leme.ufcg.edu.br/cadernosdoleme/index.php/eleme/issue/view/7; acesso: dezembro de 2017.

CHAUI, M. Manifestações ideológicas do autoritarismo brasileiro. ROCHA, A. (Org.). Escritos de Marilena Chaui, v. II, 2. ed. Belo Horizonte: Autêntica Editora; São Paulo: Editora Perseu Abramo, 2014.

Brasil: Mito fundador e sociedade autoritária. $1^{\text {a }}$ ed. São Paulo: Editora Perseu Abramo, 2014. 
COSTA, S. A mestiçagem e seus contrários - etnicidade e nacionalidade no Brasil contemporâneo. Tempo Social -Revista de Sociologia da USP, v. 13, n.1, p. 143-158, 2001. Disponível em: http://www.revistas.usp.br/ts/article/view/12354; acesso: outubro de 2017.

CUNHA, M. C. da. Cultura com aspas e outros ensaios. São Paulo: Ubu Editora, 2017. Índios no Brasil: História, Direitos e Cidadania. São Paulo: Claro Enigma, 2012.

. Os direitos do Índio: ensaios e documentos. São Paulo: Brasiliense; Comissão PróÍndio de São Paulo, 1987.

DAFLON, V. T. Mestiçagem. In: SANSONE, L.; FURTADO, C. A. (Orgs.). Dicionário crítico das ciências sociais dos países de fala oficial portuguesa. Salvador: EDUFBA, 2004. p. 309-330.

FLORES, L. D. A guerra comancheira: contribuições a uma antropologia afroindígena. Revista de Antropologia da UFSCar (R@U), v. 9, n. 2, jul./dez, p. 43-61, 2017. Disponível em: http://www.rau.ufscar.br/wp-content/uploads/2017/12/02_Luiza_Dias.pdf; Acesso: 23 de janeiro de 2018.

GOLDMAN, Márcio. Contradiscursos afroindígenas sobre mistura, sincretismo e mestiçagem - estudos etnográficos. Revista de Antropologia da UFSCar (R@U), v. 9, n. 2, jul./dez. 2017, p. 11-28. Disponível em: http://www.rau.ufscar.br/wpcontent/uploads/2017/12/introdução_dossiê.pdf; Acesso em: 23 de janeiro de 2018.

. "Quinhentos anos de contato": por uma teoria etnográfica da (contra)mestiçagem. Revista Mana - Estudos de Antropologia Social, v. 21, n. 3, p. 641-659, 2015. Disponível em: http://www.scielo.br/scielo.php?script=sci_arttext\&pid=S0104-93132015000300641; Acesso: dezembro de 2017.

Alteridade e experiência: antropologia e teoria etnográfica. Etnográfica, v. 10, n. 1, p. 161-173, 2006, Disponível em: http://www.scielo.mec.pt/scielo.php?script=sci_arttext\&pid=S0873-65612006000100008; acesso em: dezembro de 2017.

A relação afroindígena. Cadernos de Campo, São Paulo, v.23, n. 23, p. 213-222, 2014. Disponível em: http://www.revistas.usp.br/cadernosdecampo/article/view/98442; Acesso: janeiro de 2018.

LIMA, C. M. Tempo e qualidade na Vila de Cimbres: uma abordagem etnográfica da (contra)mistura. Revista de Antropologia da UFSCar (R@A), jul./dez, p. 87-108, 2017. Disponível: http://www.rau.ufscar.br/wp-content/uploads/2017/12/05_Clarissa_Martins.pdf; Acesso em: 12 de janeiro de 2018.2017. 
LUCIANI, J. A. K. Sobre a antimestiçagem. Tradução Nicole Soares, Levindo Pereira e Marcos de Almeida Matos. Curitiba, PR: Species - Núcleo de Antropologia Especulativa: Desterro, [Florianópolis]: Cultura e Barbárie, 2016.

MELLO, C. C. do A. Quatro Ecologias Afroindígenas. Revista de Antropologia da UFSCar (RAU), v. 9, n. 2, jul./dez., p. 11-29, 2017a. Disponível em: http://www.rau.ufscar.br/wpcontent/uploads/2017/12/01_Cec\%C3\%ADlia_Campelo.pdf; acesso: janeiro de 2018.

Obras de arte e conceitos: cultura e antropologia do ponto de vista de um grupo afro-indígena do sul da Bahia. (Dissertação de Mestrado), Programa de Pós-Graduação em Antropologia Social (PPGAS), Museu Nacional, UFRJ, 2003.

. "Devir-afroindígena: 'então vamos fazer o que a gente é"”. Cadernos de Campo, n. 23, p. 223-239, 2014. Disponível em: file://C:/Users/PC/Downloads/98443-171019-1PB.pdf; acesso: dezembro de 2017.

Pessoas, Acontecimentos e Objetos de Arte em um Movimento Cultural em Caravelas, Bahia. Ilha - Revista de Antropologia, v. 9, n. 1, 2, p. 169-193, 2007. Disponível em: https://periodicos.ufsc.br/index.php/ilha/article/view/7902/14996 Acesso em: 25 de março de 2017.

MUNANGA, K. Algumas considerações sobre "raça", ação afirmativa e identidade negra no Brasil: fundamentos antropológicos. Revista da USP, São Paulo, n. 68, p. 46-57, dez./fev. 2006.

Rediscutindo a mestiçagem no Brasil: identidade nacional versus identidade negra. Belo Horizonte: Autêntica, 2004a.

Uma abordagem conceitual das noções de raça, racismo, identidade e etnia. In BRANDÃO, André Augusto P. (Org.). Programa de Educação sobre o negro na sociedade brasileira. Niterói, RJ: Ed. da Universidade Federal Fluminense, 2004b.

Uma abordagem conceitual das noções de raça, racismo, identidade e etnia. Palestra. In $3^{\circ}$ Seminário Nacional Relações Raciais e Educação (PENESB), Rio de Janeiro, 05 de nov. de 2003.

NOBREGA, M. Entre "almas" e "caboclos", um "povo só": diferença e unidade numa ilha no Rio São Francisco. Revista de Antropologia da UFSCar (RAU), v. 9, n. 2, jul./dez., p. 109 122, 2017. Disponível em: http://www.rau.ufscar.br/wpcontent/uploads/2017/12/06_M\%C3\%A1rcia_N\%C3\%B3brega.pdf; acesso: janeiro de 2018.

OLIVEIRA FILHO, J. P. de (Org.). A presença indígena no Nordeste: processo de territorialização, modos de reconhecimento e regimes de memória. Rio de Janeiro: Contra Capa, 2011.

Ensaios em Antropologia Histórica. Rio de Janeiro: Editora UFRJ, 1999.

PACHECO, A. S. Afroindigenismo por escrito na Amazônia. RELACult - Revista LatinoAmericana de Estudos em Cultura e Sociedade. v. 3, ed. Especial, dez p. 1-22, 2017. \begin{tabular}{l|l} 
Revista RBBA & Revista Binacional Brasil Argentina
\end{tabular} 
Disponível em: http://periodicos.claec.org/index.php/relacult/article/view/645; acesso: fevereiro de 2018.

OLIVEIRA, C. M. de; SILVA, P. de T. B. da. Voos na sabedoria: o ensino do Patxohã na Escola Estadual Indígena Kijetxawê Zabelê. In: ZAPAROLI, Witembergue Gomes (Org). Caminhos e encontros na educação de indígenas. Imperatriz: Ethos, 2017.

PAZZARELLI, F.; SAUMA, J. F.; HIROSE, M. Be. (Contra)mestiçagens ameríndias e afroamericanas. Revista de @ntropologia da UFSCar (R@U) v. 9, n. 2, jul-dez de 2017. p. 910. São Carlos: UFSCar, 2017. Disponível em: http://www.rau.ufscar.br/index.php/2017/12/15/volume-9-numero-2-2017/ Acesso em: 12 de dez. de 2017.

PEGGiOn, E. A.; DANAGA, A. C. (Orgs.). Povos indígenas em São Paulo: novos olhares. São Carlos: EduFSCar, 2016.

RUSSELL-WOOD, A. J. R. Escravos e libertos no Brasil colonial. Rio de Janeiro: Civilização Brasileira, 2005.

SAMPAIO, J. A. L. De caboclo a índio: etnicidade e organização social e política entre povos indígenas contemporâneos no nordeste do Brasil: o caso Kapinawá. Cadernos do LEME, Campina Grande, v. 3, n. 2, p. 88-191, jul/dez, 2011. Disponível em: http://www.leme.ufcg.edu.br/cadernosdoleme/index.php/e-leme/article/view/45; $\quad$ acesso: novembro de 2017.

VAINFAS, R. Colonização, miscigenação e questão racial: notas sobre equívocos e tabus da historiografia brasileira. Tempo, Niterói, n.8, p. 1-12, 1999.

VANZOLINI, M. Daquilo que não se sabe bem o que é: a indeterminação como poder nos mundos afroindígenas. Cadernos de Campo, São Paulo, n. 23, p. 271-381, 2014. Disponível em: http://www.revistas.usp.br/cadernosdecampo/article/view/98489; acesso: janeiro de 2018.

VIEIRA, S. de A. De negros, tapuias e "quem quer ser branco": a política quilombola da diferença. In Anais do $\mathbf{4 0}^{\circ}$ Encontro Anual da Anpocs. ST01 Antropologia Afroindígenas: contradiscursos e contramestiçagens. p. 2-14. GOLDMAN, Márcio (UFRG); SZTUTMAN, Renato (UFRG) (Coords.). 24 a 28 de out. 2016. Caxambu, MG, 2016. Disponível em: http://www.anpocs.org/index.php/papers-40-encontro/st-10/st01-8 Acesso em: 30.10.2017.

\section{Sobre a autora}

Maria de Fátima de Andrade Ferreira. Professora Titular da Universidade Estadual do Sudoeste da Bahia (UESB). Licenciada em Pedagogia pela 
Fundação Educacional Nordeste Mineiro (FENM) e em História pela Universidade Estadual de Santa Cruz (UESC); Mestre e Doutora em Educação, pela Universidade Federal da Bahia; Pós-Doutoranda em Antropologia pela Universidade Federal da Bahia. Coordena o Núcleo de Pesquisa e Extensão Gestão em Educação e Estudos Transdisciplinares NUGEET e Grupo de Pesquisa Resiliência e Educação (CNPq/UESB). Coordena a Rede de Pesquisa Representações, Discursos e Violência na Escola - olhar, pensar e agir sobre a formação de valores, atitudes e permanência do aluno na sala de aula (FAPESB/UESB). Linhas de atuação em pesquisa: Diversidade, Ética e Direitos Humanos; Responsabilidade Social, Diversidade e Meio Ambiente; Violência na Escola. Estudos nas temáticas: relações étnico-raciais; Gênero e meio ambiente; responsabilidade social e violência na escola e social (urbana). Endereço Eletrônico: mfatimauesb@hotmail.com

Recebido: 30.06 .18

Aprovado: 25.07.18 